\title{
Recepção e consumo de Rebelde-RBD por parte dos jovens ${ }^{1}$
}

\author{
Fernanda Elouise Budag ${ }^{2}$ \\ Maria Aparecida Baccega ${ }^{3}$
}

\section{Resumo}

Neste texto buscamos trabalhar as questões da recepção e do consumo da telenovela Rebelde e do grupo musical $R B D$ por parte de jovens. Apresentam-se alguns resultados de uma pesquisa cujo objetivo é identificar os valores em Rebelde e contrastá-los com os percebidos pelos receptores, com a intenção de compreender as ressignificações efetuadas por estes sujeitos. Neste processo, procuram-se detectar as singularidades das identidades dos jovens receptores pesquisados, assim como as peculiaridades das práticas de consumo inseridas nesse circuito.

Palavras-chaves: Recepção; consumo; telenovela.

\begin{abstract}
This text deals with the reception and consumption of the Rebelde soap opera and the RBD music group. The paper presents the results of a research that identified the values in Rebelde in contrast with the values perceived by receivers. The study tries to understand how the subjects give new meanings to this values. In this process we want to detect the young people singular identities that were studied, as well as the peculiar consumption practices included in this circuit.
\end{abstract}

Keywords: Reception; consumption; soap opera. 


\section{Notas introdutórias}

Vamos apresentar aqui os primeiros resultados de um estudo de recepção da telenovela Rebelde realizado com jovens ${ }^{4}$ na faixa de 10 a 13 anos, dos níveis sócio-econômicos $\mathrm{A}, \mathrm{B}$ e $\mathrm{C}^{5}$ da cidade de São Paulo. O estudo de campo, em sua totalidade, compreende três abordagens junto aos receptores: (1) aplicação de questionário escrito; (2) grupos de discussão; (3) entrevistas em profundidade. As reflexões que trazemos no decorrer deste texto são resultados inferidos somente da primeira parte de nosso percurso (a aplicação do questionário), que foi realizada em dezembro de 2006 junto a estudantes de $4^{\mathrm{a}}$ e $6^{\mathrm{a}}$ séries do Ensino Fundamental ( $1^{\mathrm{a}}$ a $8^{\mathrm{a}}$ séries) de uma escola pública e de uma escola particular da capital paulistana. Consiste em um questionário com perguntas abertas que indaga o jovem a respeito de seu consumo cultural em geral (televisão, rádio, música, internet, revista, livro, celular, shopping etc), sua opinião sobre telenovelas e, mais especificamente, questões sobre recepção de Rebelde e consumo de produtos da marca Rebelde-RBD.

Uma leitura analítica dos questionários permite-nos traçar considerações e esboçar alguns resultados parciais dessa primeira etapa da pesquisa de campo. De nossa amostra de 333 questionários, selecionamos 50 que assistiam a Rebelde e responderam a maior parte das perguntas para trabalharmos com mais profundidade.

\section{Contextualização da telenovela e introdução a Rebelde e RBD}

O melodrama data do século XVIII e constitui a matriz cultural da telenovela: a telenovela apropria-se da base estética e emocional do melodrama. Efetuaram-se renovações e adaptações, porém o melodrama continua sendo a base da formação discursiva e audiovisual da telenovela.

A telenovela é um produto teledramático que arrebata 2 bilhões de pessoas no mundo inteiro $(\mathrm{O}$ PLANETA, 2007: 8). Com características que lhe são peculiares - em sua linguagem, em sua dramaturgia e nos demais elementos que a compõem -, esse gênero ficcional refrata a realidade, apresentando-a no campo simbólico, e pode chegar a promover uma verdadeira educação dos sentidos em seus receptores. No Brasil, conforme Baccega (2004: 14), "mais que mania nacional, a telenovela é manifestação de cultura e agente da dinâmica social." Ainda segundo a mesma autora,

"a telenovela, a ficção televisiva em geral (minissérie, seriado, caso especial, também chamado unitário) estão aí e, pelo próprio formato do gênero - figurativo por excelência -, conseguem, de maneira muito mais ágil, expor conceitos e caminhar com êxito no sentido da persuasão da população em geral" (BACCEGA, 2003: 8). 
Esta perspectiva de olhar para a telenovela como produto cultural de grande repercussão em nosso país (seja de telenovelas nacionais ou de telenovelas estrangeiras) é que nos motivou a estudar Rebelde, uma bemsucedida produção da rede de televisão mexicana Televisa. Bem-sucedida em termos de audiência, de países para os quais foi exportada, de número de produtos licenciados à marca, de recordes de vendas de CDs da banda vinculada à telenovela e inclusive da intensidade da emoção que provoca em seu público receptor. É uma telenovela voltada para o público jovem que mostra as festas e confusões e também alegrias e sofrimentos - sobretudo amorosos - de alunos de Ensino Médio de um colégio de elite e, a partir daí, aventura-se a discutir questões como os estereótipos e as relações familiares. Tudo isso embalado por muita música: o som pop da banda $R B D$, grupo formado no decorrer da primeira temporada de Rebelde, quando os seis protagonistas da telenovela descobrem que compartilham da paixão pela música.

Aliás, aos olhos do público em geral, $R B D$ teria emergido de Rebelde. Contudo, acreditamos que $R B D$ é apenas um dos muitos produtos para os quais Rebelde foi formatada. Essa telenovela objetiva vender produtos, sobretudo, a banda. Essa face mercadológica de Rebelde torna-se explícita quando voltamos no tempo e constatamos que, em julho de 2003, a Televisa lança sua divisão Televisa Licencias “[...] com o objetivo de explorar o potencial comercial de suas produções [...]" (REDIBRA, 2007) e Rebelde começa a ser produzida em 2004. Ou seja, é produzida numa nova fase da emissora e tudo indica que a venda de produtos relacionados a Rebelde está presente como objetivo desde o momento de sua concepção. E os números que a envolvem estão aí para comprovar sua popularidade e os resultados satisfatórios.

\section{Recepção: circulação de sentidos}

De acordo com o que já mencionamos previamente, nossa pesquisa enquadra-se no âmbito dos Estudos de Recepção. Parece-nos uma vertente das pesquisas em comunicação adequada para estudarmos a interação mídia/receptor na qual estamos interessados. Nessa corrente, a recepção é concebida como um processo de apreensão e reapropriação das mensagens por parte dos receptores. Portanto, segundo Gomes (2004: 175),

“estudar recepção não se traduz por checar se a audiência alcança os sentidos transmitidos pelos meios de comunicação. Ao contrário, 'procuram-se os diferentes sentidos que a audiência constrói' a partir das mensagens disponibilizadas pelos media. A própria 'diversidade de sentidos' construídos é muitas vezes considerada, em si mesma, testemunho da atividade dos receptores".

A recepção é, pois, um processo no qual a formação dos significados se dá de fato no receptor. É esse sujeito quem efetivamente define o significado a partir daquilo que foi emitido, do lugar em que foi emitido e do conjunto das emissões daquele produto. O processo de recepção é polissêmico e a Análise do Discurso de linha francesa - nosso procedimento de avaliação do corpus da pesquisa - leva em consideração, além de 
outros aspectos, justamente essa polissemia nos enunciados: a "multiplicidade de sentidos possíveis" (ORLANDI, 1993: 22) de um discurso.

Podemos constatar a mencionada diferença de significações que os receptores dão às mensagens recebidas da mídia - uma das preocupações de um estudo de recepção de um produto midiático - quando analisamos os enunciados que nossos entrevistados deram para a questão "Para você, o que significa ser rebelde?". Destacamos que nossas análises foram feitas sob a ótica dos diferentes níveis sócio-econômicos e, assim, compartilhamos da perspectiva de Lopes (2002: 14), segundo a qual "a diferença de classe, ainda que mediada pela multiplicidade de distinções introduzidas pela etnia, gênero, idade, entre outras, não é uma diferença a mais, mas, sim, aquela que articula as demais a partir de seu interior e expressa-se por meio do habitus, capaz de entrelaçar os modos de possuir, de estar junto e os estilos de vida".

Dessa maneira, conseguimos traçar alguns cruzamentos e disparidades entre os distintos níveis sócioeconômicos concernentes à mencionada questão - "Para você, o que significa ser rebelde?". Os integrantes do nível sócio-econômico A dividem-se claramente em dois grupos: os que vinculam a palavra rebelde a "independente" e os que a vinculam a "extrovertido". Fornecem-nos definições do tipo: ser rebelde é "ser livre (ter liberdade)"; "poder fazer o que quiser na hora que quiser"; "ser independente e ter atitude"; "ser uma pessoa travessa"; "ser legal e ser tudo" e "ser descolado". Em verdade, legal é uma palavra de significado tão aberto que deixa de ter valor para a compreensão do que foi dito.

Já nos discursos dos jovens de nível sócio-econômico B a maior ocorrência é da definição bastante generalista de rebelde como "ser legal". E começamos a encontrar, neste nível sócio-econômico, jovens que não responderam ou disseram não saber responder a questão proposta. Também encontramos as categorias "independente" e "extrovertido" que apareceram nos discursos dos entrevistados de nível sócio-econômico A: ser rebelde é "ser uma pessoa firme e forte"; "significa caráter e bom senso"; "ter muita atitude e ser independente"; "ser extrovertido" e "divertido".

No nível sócio-econômico $\mathrm{C}$ ocorre uma divergência de discurso em relação aos dois níveis imediatamente superiores. A maior ocorrência é um sentido negativo de rebelde, com expressões como: ser rebelde é "ser desobediente"; "ser uma criança malcriada e respondona"; "quando não segue as regras, é muito impaciente"; "significa jovens bagunceiros"; "significa desobedecer aos pais, mal educado e ignorante"; "ser mal educado e que não fica respeitando os mais velhos" e "significa ser muito respondona, agitada". São valores conservados pela cultura que, em geral, não são seguidos - apenas ditos - pela geração que os divulga. São tradicionais.

Mesmo tendo a clareza de que, em se tratando de um estudo de recepção, estamos mais interessados em verificar os sentidos que a fala do emissor possibilitou - de acordo com as várias mediações dos receptores do que o significado possível atribuído pelo emissor, consideramos fundamental o levantamento de temáticas (e suas respectivas valorações) que reconhecemos em Rebelde. Não só como uma maneira de ilustrar a 
ressignificação empreendida pelos emissores, mas também levar em consideração o que diz Hall (2003: 387), segundo o qual é

“[...] possível (e útil) pensar esse processo [de comunicação] em termos de uma estrutura produzida e sustentada através da articulação de momentos distintos, mas interligados - produção, circulação, distribuição/consumo, reprodução. Isto seria pensar o processo como uma 'complexa estrutura em dominância', sustentada através da articulação de práticas conectadas, em que cada qual, no entanto, mantém sua distinção e tem sua modalidade específica, suas próprias formas e condições de existência”.

Dentre as muitas temáticas abordadas por Rebelde, identificamos quatro principais que permeiam toda a telenovela: amizade, amor, família e rebeldia. A representação principal de amizade traduz-se na expressão "o bem mais valioso de uma pessoa", proferida por um personagem do núcleo central da telenovela. Essa representação de amizade complementa o sentido que é dado para a rebeldia, que seria a "luta contra as injustiças". Isto porque, na história de Rebelde, esta luta é uma união de forças dos amigos para realizarem manifestações contra o que consideram errado. Um "certo" e um "errado" que obedecem aos padrões tradicionais da sociedade.

Já a figura representativa do amor seria o ciclo sofrimento / final feliz, tal qual a estrutura tradicional do drama. A respeito das representações da família, verificamos que esta possui variadas figurações e destacamos aqui a representação da família como fonte de sofrimento: pais que tolhem a liberdade de seus filhos, a mãe que decepciona a filha e demais situações de dramas familiares similares. Não é a única representação da família, mas é uma que aparece com freqüência.

Com isto, podemos deduzir que Rebelde pôs em circulação representações de rebeldia que, recebidas, foram ressignificadas; e hoje o termo remete a novos sentidos construídos. Por exemplo, mesmo que tenhamos observado na telenovela a rebeldia como uma luta, uma atitude pró-ativa, muitos dos jovens receptores afirmam que ser rebelde é ser legal. Ou seja, a rebeldia esvaziou-se de significados.

\section{A construção de identidades: manifestações}

Adotando a noção de que "os processos através dos quais as produções culturais interpelam o espectador e o modo como se dá a incorporação de seus elementos às práticas cotidianas são profundamente subjetivos" (LOPES, 2002: 181-182), tentamos captar como se dá a construção das identidades de nossos jovens entrevistados.

Entendemos que "[...] a identidade é um processo de fazer-se, individualmente e coletivamente, na experiência social com os repertórios disponíveis ou desejados que são confrontados ou abandonados de acordo com a circunstância e a conveniência" (RONSINI, 2007: 66). Sendo assim, por meio da análise do discurso de nossos jovens entrevistados, buscamos elementos que remetessem às cenas de que mais gostam, 
aos personagens com quem consideram se parecer, aos motivos que os levam a assistir a Rebelde e aos produtos que consomem para construirmos um quadro com categorias no qual suas identidades tendem a encaixar-se. Falamos em "tendência" de identidade porque temos consciência da fluidez e efemeridade das identidades contemporâneas, muitas vezes construídas e descontruídas ao "trocar-se de roupa". E, na sociedade contemporânea, as modificações sucedem-se mais rapidamente, como lembra Hall (2006), falando da fragmentação na chamada pós-modernidade.

Enfim, em nosso estudo, percebemos quatro possíveis principais meios de manifestação das identidades entre os jovens entrevistados, quais sejam: (1) pelo perfil; (2) pelas motivações; (3) pelo gosto; (4) pelo consumo. Por meio do perfil, observamos que há os sujeitos que manifestam suas identidades no plano da aparência (o visual) e há os que revelam essas identidades no plano do comportamento (conduta).

Quanto ao perfil (categoria 1), os jovens de nível sócio-econômico A tendem a pertencer ao segundo grupo (comportamento), pois em seu discurso podemos perceber que mencionam possuir marcas identitárias similares às das personagens sempre no âmbito do comportamento. Algumas das características citadas por eles são: "esperta" e com "personalidade" como Roberta; “jeitosa” como Lupita e "delicada" como Pilar.

O nível sócio-econômico $\mathrm{B}$, pelo perfil, abrange as duas tendências de planos de manifestação das identidades. No primeiro plano, temos atributos como: "magrinha" como Mía; "rosto" igual ao de Diego e "morena" como Lupita. Enquanto no outro plano vemos as características que seguem: "jeito” de Mía e Lupita; "metida e fresca" como Mía; "teimosa" e com "atitudes" como de Roberta.

Da mesma forma, no nível sócio-econômico $\mathrm{C}$, verificamos a incidência dos dois conjuntos de categorias de manifestação das identidades pelo perfil. Quanto à aparência, são freqüentes menções como: "rosto" e "cabelo" de Diego; "bonita" como Lupita; "bonita", "loira" e da mesma "cor" de Mía e o "nariz" como o de Lupita. Quanto ao comportamento, “exibida", "sensível”, "delicada" e "fresca" como Mía; “irritada" como Roberta; “meiga” como Lupita e "ajuda os amigos” como Miguel.

Por meio de suas motivações (categoria 2) - ou seja, o porquê, o motivo que leva os receptores pesquisados a assistirem a Rebelde -, notamos que suas identidades constroem-se impulsionadas por dados que designamos serem de natureza "generalista", "informacional”, "relativista" e "musical”.

Os jovens de nível sócio-econômico A apresentam-se com motivações de natureza "generalista", na medida em que se limitaram a dar explicações abstratas, utilizando palavras como: assisto a Rebelde porque é "legal”, porque é "demais", "porque é divertida". Notamos que permanecem no nível superficial do discurso, sem adentrar o nível profundo, e acreditamos que isto ocorreu de maneira uniforme no nível sócio-econômico A dessa amostra pelo fato de todos serem alunos da $4^{\text {a }}$ série do Ensino Fundamental e, por não possuírem maior domínio da língua, não conseguiram expressar-se com maior articulação.

"Porque eu gosto" - um exemplar do discurso que estamos chamando de generalista - é extremamente presente no discurso dos pertencentes ao nível sócio-econômico B. Embora existam sujeitos desse nível sócio- 
econômico que exprimem motivações de natureza "generalista", há muitos outros receptores que oferecem pistas mais detalhadas para pensarmos sobre os elementos que são empregados nessa telenovela para conseguir conquistar a preferência de jovens de todo o planeta e, logo, alcançar pistas para os interesses desses jovens interesses estes que compõem suas identidades. Os jovens de nível sócio-econômico B revelam motivações de natureza que estamos chamando de "informacional", que seguem nesta linha: assisto a Rebelde porque "mostra que tudo se resolve não gritando e sim conversando"; "passa muitas coisas que são reais na vida. São coisas que acontecem"; "ensina a conhecer a si próprio" e "essa novela é rebelde, para jovens, conta casos curiosos, fala sobre problemas amorosos, etc."

Em certo grau, nos enunciados dos jovens de nível sócio-econômico B, conseguimos notar uma percepção de verossimilhança das representações da telenovela com as práticas cotidianas vivenciadas pelos receptores. Ou seja, esses sujeitos não enxergam a telenovela como "representação" do real, e sim como o próprio real. Dialogamos então com Vattimo (1992: 31-32), que problematiza questões desse âmbito e afirma que "as imagens do mundo que nos são fornecidas pelos media [...] constituem a própria objetividade do mundo, e não apenas interpretações diferentes de uma 'realidade' de algum modo 'dada'”.

Já entre os receptores do nível sócio-econômico C encontramos jovens representantes de três naturezas de motivação: "generalista", "musical" e "relativista". Da mesma forma que os níveis sócio-econômicos anteriores, a natureza "generalista" das motivações de muitos jovens do nível sócio-econômico C se expressa com sentenças como: assisto a Rebelde "porque eu gosto", "porque é legal” e "porque é interessante". O que percebemos, porém, é a grande ocorrência - nula nos demais níveis sócio-econômicos - de menções de motivações de natureza "musical”. Isto é, fazendo referência à face musical da telenovela Rebelde com menções do tipo: assisto a Rebelde porque "é legal o grupo"; "tem músicas"; "eles cantam, eles têm a voz muito bonita”. Os jovens de nível sócio-econômico C tendem também a expressar motivações de natureza "relativista", contrabalançando afirmações seguidas de negações. Dizem, por exemplo, que assistem a Rebelde porque "é muito legal. Mas a gente pode assistir mas não pode fazer igual a eles" e "ensina muitas coisas legais mas nem todas".

No que diz respeito aos gostos (categoria 3) que compõem suas identidades, mais especificamente sobre de que tipo de cenas os receptores mais gostaram em Rebelde, reconhecemos gostos de três tipos: "cenas amorosas"; "cenas de shows" e "cenas com personagens adultas".

Para os jovens de nível sócio-econômico A, segundo seus discursos, a maior tendência de seus gostos recai em "cenas amorosas": beijos e início de namoros. As inclinações dos sujeitos pertencentes ao nível sócioeconômico B dividem-se entre as "cenas amorosas" (cenas protagonizadas por pares românticos) e as "cenas de shows" (os espetáculos de $R B D$ representados na telenovela).

Por fim, inseridos no nível sócio-econômico $\mathrm{C}$, há os sujeitos com gostos propensos às "cenas amorosas" (os namorados), às "cenas de shows" e, o que chama a atenção, diferentemente dos demais níveis 
sócio-econômicos, emerge o tipo "cenas com personagens adultas". Por exemplo, é citada a cena em que Roberta declara em público seu amor e admiração à mãe durante um show e também os episódios em que Alma Rey (mãe de Roberta) namora Franco Colucci (pai de Mía).

O último meio de manifestação das identidades que arrolamos, como já apontamos, é o consumo (categoria 4). Deixamos este "meio de expressão" para o final porque pretendemos desenvolvê-lo um pouco mais em relação aos anteriores. Concebemos o consumo, seguindo as reflexões de Everardo Rocha (1995), como uma prática de cultura e um sistema de significação, que possui um plano simbólico e, por isso, comunica sentidos, estilos, identidades e diferenças.

Rocha fala a partir da Comunicação de Massa e podemos aproveitar-nos de suas reflexões para, partindo da telenovela - sistema de produções simbólicas -, pensarmos a respeito do consumo. Para Rocha (1995: 36), ocorre entre a Indústria Cultural (onde a telenovela se insere) e a sociedade "[...] um jogo sistemático de trocas, envolvendo valores, estilos de vida, emoções, heróis, rituais, mitos, representações [...]". Esse jogo veiculado pela telenovela ocorre numa esfera simbólica e essas "representações" acabam, inevitavelmente, transferindo-se para o consumo. Desse modo, agrega-se ao valor material e simbólico próprio do objeto outro valor "emprestado" pela mídia. É esse um importante agenciador das identidades.

O consumo é, pois, um dos componentes das identidades. Ao menos algumas esferas das identidades são construídas pelo consumo. Em nossa pesquisa, distinguimos os diferentes sujeitos receptores de Rebelde$R B D$ pela intensidade e categoria de produtos que consomem. De acordo com a intensidade, observamos então três grupos de consumidores que correspondem a, digamos, "condutas" de consumo e não deixam de ser, obviamente, manifestações das identidades. Esses três grupos são: o "consumidor dispendioso"; o "consumidor mediano" e o "consumidor intenso". Analisando as categorias de produtos consumidos, também conseguimos pincelar traços de suas identidades sendo expressas nessas práticas de consumo. Dessa maneira, agrupamos os bens materiais consumidos por nossos jovens entrevistados em cinco grandes categorias: "utilidade" (papelaria, livro, malas etc); "entretenimento" (bonecas, celular, CD, DVD etc); “colecionáveis” (revistas, álbuns, cards, fotos etc); "vestimenta" (uniforme, camiseta, sapato, tênis etc); "acessórios" (brinco, anel, colar etc) e “cosméticos" (xampu, gel, perfume, condicionador etc).

Antes de tudo, notamos que o consumo perpassa todos os níveis sócio-econômicos, sem exceção. No entanto, foi nítido perceber em nosso estudo (ver Gráfico 1 abaixo) como a quantidade de produtos cresce à medida que descemos na escala de níveis sócio-econômicos. No nível sócio-econômico A, obtivemos uma média de 1,3 produtos comprados por consumidor; no nível $\mathrm{B}, 2,2$ produtos por consumidor e, no nível C, 2,5 produtos por consumidor. Ou seja, o oposto da condição econômica. Dialogamos, então, com Hamburger (2005: 54), que afirma que o nível sócio-econômico C seria o segmento mais essencial para as emissoras de TV no Brasil porque, “[...] embora possua menos recursos para gastar, seus membros representariam uma porção maior da população brasileira, além de supostamente consumirem mais que membros das classes B". 


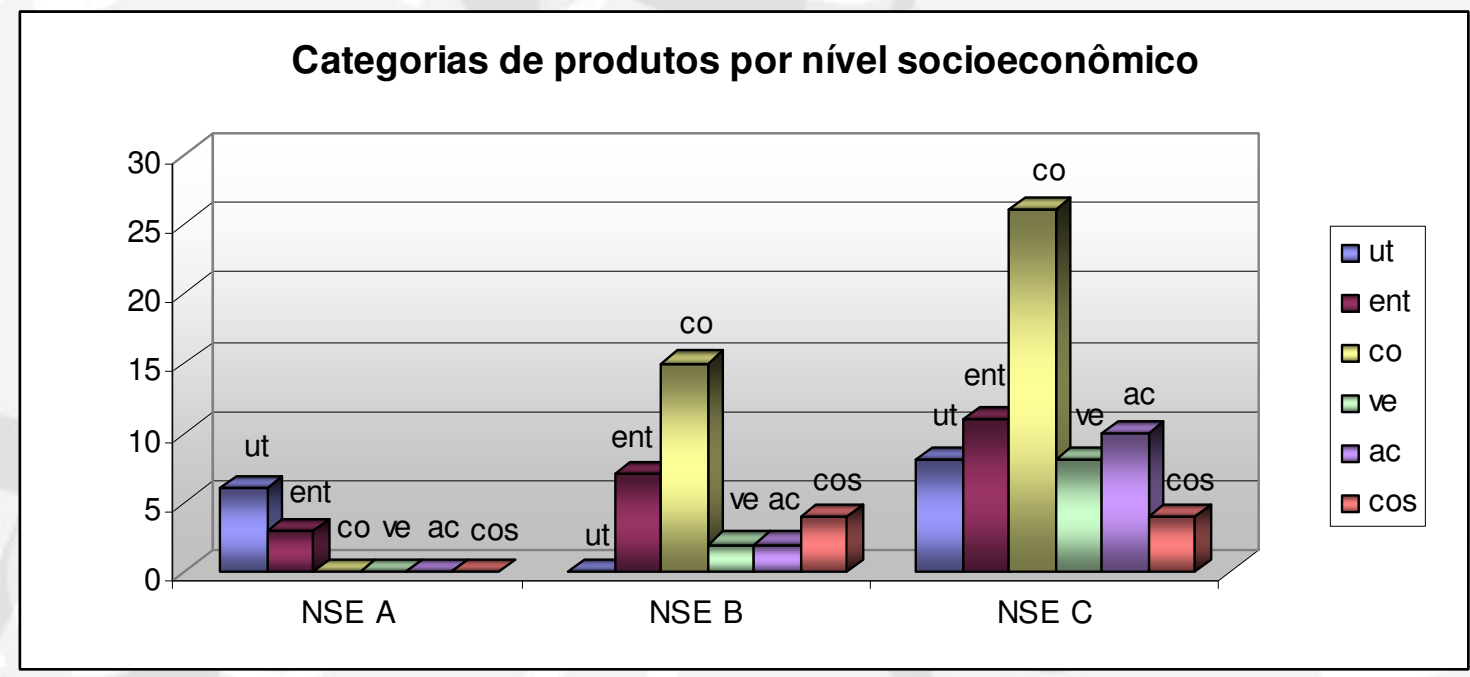

* ut $=$ utilidade $/$ ent $=$ entretenimento $/ \mathrm{co}=$ colecionáveis $/ \mathrm{ve}=$ vestimenta $/ \mathrm{ac}=$ acessórios $/ \cos =\operatorname{cosmético}$

Gráfico 1 - Categorias de produtos por nível sócio-econômico

Fonte: pesquisa realizada em dez/2006 com jovens de 10 a 13 anos, na cidade de São Paulo.

No consumo, as marcas identitárias dos entrevistados do nível sócio-econômico A tendem a se manifestar, de acordo com a intensidade de compra, como "consumidor dispendioso" e, segundo as categorias dos produtos que consomem, inclinam-se para os produtos de "utilidade" e de "entretenimento" (celulares, CDs e DVDs). Quando falamos em "consumidor dispendioso", usamos o termo no sentido de que é o nível sócio-econômico que, em nossa pesquisa, compra menos em quantidade, mas despende mais recursos para o consumo de bens materiais mais caros, como celulares. Aliás, celulares e livros, mencionados pelos sujeitos do nível sócio-econômico A, são produtos que estão completamente ausentes nos demais níveis. No caso de um produto como o livro, por exemplo, cremos que não conste na lista de consumo dos níveis inferiores justamente porque sua aquisição não é prioridade. Quanto ao celular, sua falta nos demais níveis deve ter ocorrido porque na época da aplicação do questionário o celular Rebelde ainda estava em lançamento e, como deveria estar com um valor mais elevado, a renda inferior dos sujeitos de níveis B e C impossibilitava o acesso a esse produto, mesmo com a maior oferta de crédito facilitado.

Para o nível sócio-econômico B, verificamos que suas identidades são expressas no sentido de um "consumidor mediano", que consome, mas não consome em excesso. Tende a consumir em maior quantidade produtos que estamos chamando de "colecionáveis", em que classificamos álbuns, cards, revistas e pôsteres. Como segunda categoria de produtos mais consumidos por esses sujeitos aparece o "entretenimento", na figura de CDs e DVDs de Rebelde e RBD.

Já o nível sócio-econômico C inclina-se para um consumidor do tipo “intenso", porque se apresenta como o mais engajado, o mais apaixonado entre os demais. Como já dissemos, possui a maior cota de produtos por pessoa. Tende a ser um consumidor disparado de "colecionáveis" de todos os tipos: fotos, cards, álbuns, 
pôsteres e revistas. Pensamos que essa prática de consumo dos integrantes do nível C é decorrência do fato de esses produtos serem de valor monetário mais barato e, portanto, mais acessíveis a sujeitos que possuem um poder aquisitivo menor. Além de consumirem em grau elevado esses produtos "colecionáveis", os sujeitos do nível C também consomem de maneira mais ou menos equilibrada mais quatro categorias de produtos: "utilidade" (papelaria); "entretenimento" (bonecas, CD e DVD); "vestimenta" (uniforme, camiseta e tênis) e “acessórios" (brinco, colar, etc).

Tentamos sintetizar na tabela abaixo (Tabela 1) o quadro que nos fornece um panorama das vias pelas quais podemos perceber os planos em que Rebelde atua fornecendo material para a constituição das identidades dos jovens pesquisados.

Tabela 1 - Meios de manifestação das identidades

\begin{tabular}{|c|c|c|c|}
\hline Perfil & NSE A & NSE B & NSE C \\
\hline comportamento & $\begin{array}{c}\text { Nos planos do } \\
\text { comportamento e da } \\
\text { aparência }\end{array}$ & $\begin{array}{c}\text { Nos planos do comportamento e } \\
\text { da aparência }\end{array}$ \\
\hline Gotivação & De natureza generalista & $\begin{array}{c}\text { De natureza generalista } \\
\text { e informacional }\end{array}$ & $\begin{array}{c}\text { De natureza generalista, musical } \\
\text { e relativista }\end{array}$ \\
\hline Gosto & Aprecia cenas amorosas & $\begin{array}{c}\text { Aprecia cenas amorosas e } \\
\text { cenas de shows }\end{array}$ & $\begin{array}{c}\text { Aprecia cenas amorosas, cenas } \\
\text { de shows e cenas com } \\
\text { personagens adultas }\end{array}$ \\
\hline & $\begin{array}{c}\text { Consumidor } \\
\text { dispendioso. } \\
\text { Tende a consumir } \\
\text { produtos de utilidade e } \\
\text { entretenimento }\end{array}$ & $\begin{array}{c}\text { Consumidor mediano. } \\
\text { Tende a consumir mais } \\
\text { produtos colecionáveis e, } \\
\text { em menor grau, produtos } \\
\text { de entretenimento }\end{array}$ & $\begin{array}{c}\text { Consumidor intenso. } \\
\text { Tende a consumir em maior } \\
\text { grau produtos colecionáveis. } \\
\text { Mas também consome produtos } \\
\text { de utilidade, de entretenimento, } \\
\text { vestimenta e acessórios }\end{array}$ \\
\hline
\end{tabular}

Finalmente, podemos inferir que essa presença explícita do consumo em todos os níveis sócioeconômicos pode ser explicada de maneira diferente para o nível superior e para os níveis mais abaixo na escala. Pensamos da seguinte maneira: os integrantes de nível sócio-econômico mais elevado procuram no consumo um meio para a diferenciação e, dessa forma, mesmo recorrendo a produtos massificados, tendem a ser mais seletivos. Já os representantes de níveis sócio-econômicos mais abaixo na escala (em nosso caso, nível C) aderem ao consumo de forma aspiracional, buscando uma equivalência (ao menos na aparência) com os sujeitos acima na escala socioeconômica. Dessa forma, sem um critério de seleção rigoroso e sem perceberem que tal equivalência não ocorrerá, acabam consumindo mais em termos de quantidade. Se buscarmos referências em Kellner (2001: 335), acabam todos recaindo na “[...] criação de um novo 'eu-mercadoria' por meio do consumo e dos produtos da indústria da moda." 


\section{Considerações finais}

Propositalmente, não incluímos nas perguntas do questionário que aplicamos nenhuma menção à banda $R B D$. Fizemos menção somente à telenovela Rebelde justamente para verificarmos se a banda seria mencionada espontaneamente. Por exemplo, perguntamos "Quais os produtos da telenovela Rebelde que você conseguiu comprar?" quando poderíamos ter questionado "Quais os produtos de Rebelde e RBD que você conseguiu comprar?". De fato, o gosto pelas músicas, pela banda, pela voz dos cantores, assim como a compra de CDs e DVDs (que são produtos da banda e não da telenovela), está fortemente presente nos enunciados externados espontaneamente como resposta a diversas questões. Podemos dizer que é indício do grande êxito da estratégia da Televisa de vender uma banda por mediação de uma telenovela.

Neste nosso estudo de recepção, ao confrontarmos os valores que reconhecemos em Rebelde aos valores que conseguimos identificar nos discursos de nossos entrevistados, vemos que a maior dessemelhança acontece no nível sócio-econômico $\mathrm{C}$ no que diz respeito à família. Isso acontece porque percebemos que foram os únicos que fizeram alusão à família em seus discursos, seja no momento em que afirmaram um lado negativo da rebeldia, de desobediência aos pais, ou quando elegeram uma cena emocionada de declaração de amor da filha para a mãe como a cena de que mais gostaram. Aqui fica uma pergunta: com valores tão díspares, como a telenovela consegue mesmo assim fazer sucesso entre esses receptores? Uma das respostas possíveis reside no êxito que os criadores da telenovela tiveram ao arrolar todos esses temas. Mas consideramos que o caminho mais adequado passa pelo que diz Ronsini (2007: 14-15):

"no final das contas, o desejo de liberdade, a ousadia e o inconformismo se resumem ao poder de comprar um estilo 'próprio' e os significados que caracterizam a juventude contemporânea acabam por estar em comunhão com a economia capitalista".

De certa maneira, a reflexão de Ronsini parece resumir bem a articulação entre consumo e identidades agenciada por uma telenovela que possui um título que remete à transgressão, mas que, inserida na cultura midiática, parece esvaziar-se de ideais. Da mesma maneira, seus receptores nada possuem de rebeldia contra a sociedade do consumo. Bem pelo contrário. Como vimos, colaboram para a manutenção do consumo supérfluo, muito incentivado, por sinal, pela própria telenovela de que são receptores. 


\section{Referências bibliográficas}

BACCEGA, Maria Aparecida. "Do mundo editado à construção do mundo". Comunicação \& Educação, São Paulo, n.1, set-dez 2004, p.7-14.

BACCEGA, Maria Aparecida. "Narrativa ficcional de televisão: encontro com os temas sociais".

Comunicação \& Educação, São Paulo, n.26, jan-abr 2003, p.7-16.

GOMES, Itania Maria Mota. Efeito e recepção: a interpretação do processo receptivo em duas tradições de investigação sobre os media. Rio de Janeiro: E-papers, 2004.

HALL, Stuart. A identidade cultural na pós-modernidade. $11^{\mathrm{a}}{ }^{\mathrm{e}}$ ed. Rio de Janeiro: DP\&A, 2006.

HALL, Stuart. “Codificação/decodificação”. In: HALL, Stuart. Da diáspora: identidades e mediações culturais. Belo Horizonte: Editora UFMG; Brasília: Representação da UNESCO no Brasil, 2003.

HAMBURGER, Esther. O Brasil antenado: a sociedade da novela. Rio de Janeiro: Jorge Zahar, 2005.

KELLNER, Douglas. A Cultura da mídia - estudos culturais: identidade e política entre o moderno e o pósmoderno. Bauru (SP): Edusc, 2001.

LOPES, Maria Immacolata Vassallo de; BORELLI, Silvia Helena Simões; RESENDE, Vera da Rocha. Vivendo com a telenovela: mediações, recepção, teleficcionalidade. São Paulo: Summus, 2002.

O PLANETA tem 2 bilhões de noveleiros. O Estado de S. Paulo, São Paulo, 21 out. 2007, Caderno TV \& Lazer.

ORLANDI, Eni Pulcinelli. Discurso e leitura. São Paulo: Cortez; Campinas (SP): Editora da Universidade Estadual de Campinas, 1993.

REDIBRA. Uma propriedade da Televisa. Disponível em: <http://www.redibra.com.br/site/>. Acesso em: 11 fev. 2007.

ROCHA, Everardo P. Guimarães. A sociedade do sonho: comunicação, cultura e consumo. Rio de Janeiro: Mauad, 1995.

RONSINI, Veneza Mayoara. Mercadores de sentido: consumo de mídia e identidades juvenis. Porto Alegre: Sulina, 2007.

RONSINI, Veneza V. Mayora. "Mídia, cultura e classe: a ordem da diferença". In: XVI Encontro Anual Da Associação Nacional Dos Programas De Pós-Graduação Em Comunicação, Curitiba, 2007. In: Anais do $16^{\circ}$ Encontro Anual da Associação Nacional dos Programas de Pós-graduação em Comunicação. Curitiba: Compós, 2007.

VATTIMO, Gianni. A sociedade transparente. Lisboa: Relógio D’Água, 1992. 


\footnotetext{
${ }^{1}$ Texto apresentado ao X Congreso Ibercom (Guadalajara, México, 2007)

${ }^{2}$ Fernanda Elouise Budag (fernanda_eb@yahoo.com.br)

Bacharel em Comunicação Social (Universidade Regional de Blumenau - FURB), mestranda do Programa de Mestrado em Comunicação e Práticas de Consumo (Escola Superior de Propaganda e Marketing - ESPM)

${ }^{3}$ Maria Aparecida Baccega (mbaccega@espm.br)

Livre-docente (Universidade de São Paulo - USP), docente/pesquisadora do Programa de Mestrado em Comunicação e Práticas de Consumo (Escola Superior de Propaganda e Marketing - ESPM)

${ }^{4}$ Esclarecemos que adotamos os termos "criança" e "adolescente" segundo as definições do Estatuto da Criança e do Adolescente, em vigor no Brasil, que considera criança os sujeitos até 12 anos de idade incompletos e, adolescente, os sujeitos entre 12 e 18 anos de idade. E quando usamos a palavra "jovens" estamos nos referindo aos dois grupos (criança e adolescente).

${ }^{5}$ Para a atribuição dos níveis sócio-econômicosócio-econômicos fazemos uso do "Critério de Classificação Econômica Brasil" (CCEB), mais conhecido por "Critério Brasil". É elaborado pela Associação Brasileira de Empresas de Pesquisa (ABEP) e utilizado pelas empresas de pesquisa e comunicação, sobretudo, para a divisão das verbas de publicidade. O CCEB estima o poder de compra dos indivíduos e famílias urbanas com base no Levantamento Sócio-econômicoSócio-econômico (LSE) do Instituto Brasileiro de Opinião Pública e Estatística (IBOPE), classificando-os por classes econômicas, abandonando a pretensão de classificar a população em termos de "classes sociais".
} 